\title{
BILATERAL LOCALIZED PIGMENTED VILLONODULAR SYNOVITIS OF THE KNEE: CASE REPORT AND REVIEW
}

\section{SINOVITE VILONODULAR PIGMENTADA LOCALIZADA E BILATERAL DOS JOELHOS. RELATO DE CASO E REVISÃO}

\author{
Tiago Lazzaretti Fernandes ${ }^{1}$, Livia Dau Videira ${ }^{1}$, Sandra Umeda Sasaki ${ }^{2}$, Renato José Mendonça Natalino ${ }^{1}$, \\ adriano Marques de Almeida ${ }^{1}$, André Pedrinelli ${ }^{1}$, Arnaldo José Hernandez ${ }^{1}$
}

1. Institute of Orthopedics and Traumatology, Hospital das Clinicas (HCFMUSP), Faculdade de Medicina, Universidade de São Paulo, São Paulo, SP, Brazil. 2. Universidade Cidade de São Paulo, Public Employee Medical Assistance Institute of São Paulo State, São Paulo, SP, Brazil.

\section{ABSTRACT}

Objectives: Several cases of bilateral diffuse pigmented villonodular synovitis (PVNS) or tenosynovial giant cell tumor have been described in the literature. Nevertheless, some presentations are rare and differential diagnoses are necessary. Methods: The purpose of this study was to perform a systematic review of the literature related to PVNS and to report a rare supra-patellar bilateral and focal presentation. We performed a systematic data review in the Pubmed Clinical Queries database using MeSH and keywords related to PVNS and tenosynovial giant cell tumor. Results: Two cases of bilateral and local PVNS had been previously described, but neither was localized in the supra-patellar compartment. To our knowledge, this case report is the first to describe supra-patellar bilateral and localized PVNS of the knee. This case involves a 28 -year-old woman with bilateral localized PVNS of the supra-patellar recess of the knee. MRI showed a low-signal intensity nodule in T1- and T2-weighted images. These were associated with hemosiderin pigmentation. Conclusion: The most important finding of the case reported is related to rarity and location. Histopathology analysis confirmed a rare case of hemosiderin pigmentation in the capsular nodule with internal non-pigmented villous content. Lipoma arborescens in the supra-patellar form must be ruled out as a differential diagnosis since it occurs in the same site. Level of Evidence IV; Case series.

Keywords: Pigmented villonodular synovitis. Review, literature. Knee. Case reports.

\section{RESUMO}

Objetivos: Diversos casos de sinovite vilonodular pigmentada difusa bilateral (SVNP) ou tumor de células gigantes tenossinoviais foram descritos na literatura. Entretanto, algumas apresentações são raras e o diagnóstico diferencial é necessário. Métodos: O objetivo do estudo foi realizar uma revisão da literatura relacionada à SVNP e relatar uma apresentação de forma bilateral e localizada rara na região supra-patelar. Foi realizada uma revisão dos bancos de dados do Pubmed Clinical Queries, MeSH e unitermos relacionados com SVNP e tumor de células gigantes tenossinoviais. Resultados: Dois casos de SVNP bilateral e local foram descritos anteriormente. No entanto, nenhum deles foi localizado no compartimento supra-patelar. Até onde sabemos, este relato é o primeiro caso descrito de SVNP bilateral localizada supra-patelar. Apresentamos uma mulher de 28 anos com SVNP bilateral no recesso supra-patelar do joelho. A RM mostrou baixo sinal dos nódulos nas imagens ponderadas em T1 e T2, associados ao pigmento hemossiderina. Conclusão: O achado mais importante está relacionado à raridade e localização. A histopatologia confirmou um caso raro de pigmento de hemossiderina no nódulo da cápsula com conteúdo viloso não pigmentado internamente. O diagnóstico diferencial com lipoma arborescens na forma supra-patelar é necessário devido à localização comum. Nível de Evidência IV; Série de casos.

Descritores: Sinovite pigmentada vilonodular. Revisão de literatura. Joelho. Relatos de casos.

Citation: Fernandes TL, Videira LD, Sasaki SU, Natalino RJM, Almeida AM, Pedrinelli A, Hernandez AJ. Bilateral localized pigmented villonodular synovitis of the knee: case report and review. Acta Ortop Bras. [online]. 2018;26(3):183-6. Available from URL: http://www.scielo.br/aob.

\section{INTRODUCTION}

Pigmented villonodular synovitis (PVNS) is a proliferative and inflammatory disease with benign outcome. ${ }^{1}$ PVNS presents either in a localized form, with minimal rates of recurrence after surgical resection, or in a diffuse form, with an expansive growth pattern showing formation of osseous erosions and extra-articular manifestation. In the diffuse form, high recurrence rates occur due to total synovectomy.

Typically, only one single joint, the knee in $80 \%$ of cases, is involved with diffuse PVNS. Reports of bi- or multiarticular manifestation are rare. ${ }^{1}$

All authors declare no potential conflict of interest related to this article. 
The first description of PVNS is commonly attributed to Chassaignac ${ }^{2}$ in 1852. In 1941, Jaffe et al. ${ }^{3}$ recognized the common histological appearance of this proliferative disease of the joint's synovial membranes, bursae, and tendon sheaths that is characterized by lipid charged macrophages, multinucleated giant cells, and deposits of hemosiderin within a fibrous stroma. ${ }^{4}$

In 1976, Granowitz et al. ${ }^{5}$ distinguished a localized form, with minimal rates of recurrence after removal and a diffuse, highly recurrent form affecting a joint's entire synovial membrane with the capacity of eroding adjacent bone and soft tissue. ${ }^{4}$

\section{METHODS}

The purpose of this study was to perform a systematic review of literature related to localized pigmented villonodular synovitis reports about the knee and to present a rare supra-patellar bilateral and focal example.

This is a systematic literature review study conducted according to PRISMA (Preferred Reporting Items for Systematic Reviews and Meta-Analysis) guidelines.

We performed a systematic review of literature available on PubMed from 1947 to 2015 using "pigmented villonodular synovitis" OR "pigmented villonodular synovitis [MeSH Major Topic] "AND "knee" OR "knee[ MeSH Major Topic]".

The selection of articles was performed by two authors (TLF and LDV). The studies maintained were evaluated based on their abstract and were excluded articles that did not refer to "pigmented villonodular synovitis" or were written in a language other than English. Case reports and case series were included.

For each study meeting the inclusion criteria, information about which articular joint, and diffuse or localized form were collected. Afterwards, we reported a bilateral focal knee involvement in a 28 years old woman and discussed the differential diagnosis with lipoma arborescens, which has a similar presentation.

The patient signed the informed consent form for participation on this Case Report and for publishing, in assigned number protocol IOT-1232, from the Scientific Commission of the Department of Orthopaedic and Traumatology, University of São Paulo, Medical School, São Paulo, Brazil.

\section{RESULTS}

Using the defined strategies, we found 563 articles corresponding to primary and sub-primary terms related to "pigmented villonodular synovitis" OR "pigmented villonodular synovitis [MeSH Major Topic]", that were selected by title and abstract.

Two cases of bilateral and local PVNS were described before. However, none of them was localized in supra-patellar compartment. The most important finding of the case reported presented below is related to rarity and location.

\section{Case report}

A 28 year-old-woman with a 20 year history of intermittent pain and swelling of both knees presented at Orthopedics and Traumatology Institute, University of São Paulo Medical School. The pain started at her right knee, and four years later appeared on her left knee. There was no history of trauma. The pain worsened with physical activity and knee flexion. Relieve was achieved with stretching.

She attended several physiotherapy sessions, without improvement. Physical examination revealed pain in suprapatellar area of both knees. Magnetic resonance imaging (MRI) (Figures 1, 2 and 3) of both knees showed a synovial hyperplasia of the suprapatellar recess with several areas of fat sign. These findings suggested the following differential diagnosis, chronicle synovitis, metaplasia and lipoma arborescens.

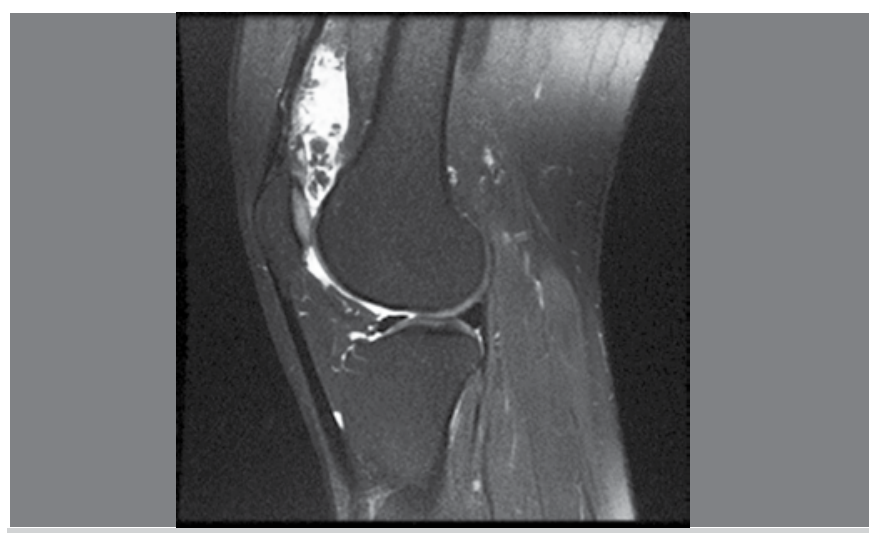

Figure 1. Sagittal imaging of the right knee (Magnetic resonance - T2 weighted signal). Note vilonodullar pattern in the anterior and superior recess.

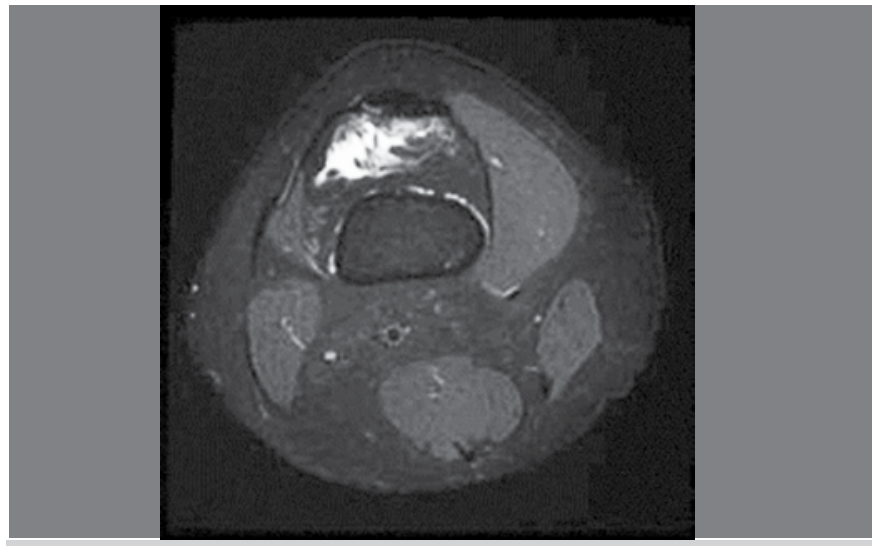

Figure 2. Axial imaging of the left knee (magnetic resonance - T2 weighted signal). Note vilonodullar pattern in the anterior and superior recess.

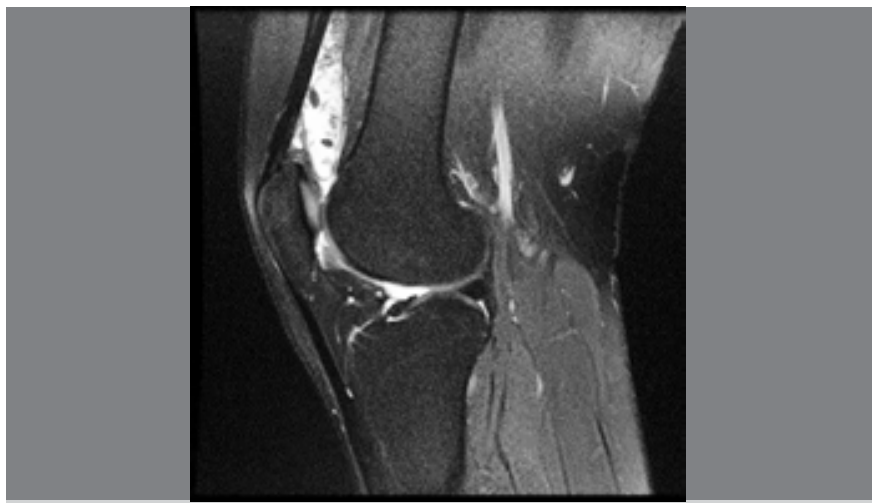

Figure 3. Sagittal imaging of the left knee (magnetic resonance - T2 weighted signal). Note vilonodullar pattern in the anterior and superior recess.

Focal PVNS was suspected based on these findings and arthroscopic surgery with synovectomy and additional biopsy was performed in left (Figure 4) and right (Figure 5) knees.

The surgery on the right knee was performed first, and 15 days later synovectomy of the left knee was performed. Macroscopic (Figure 6) and histological analysis revealed findings that were consistent with diagnosis of PVNS of both knees. (Figure 7 and 8)

After the procedure, she received multiple physiotherapy sessions, showing a total pain improvement after two months. Moreover, she showed no signs of infection, and made a routine postoperative recovery. 


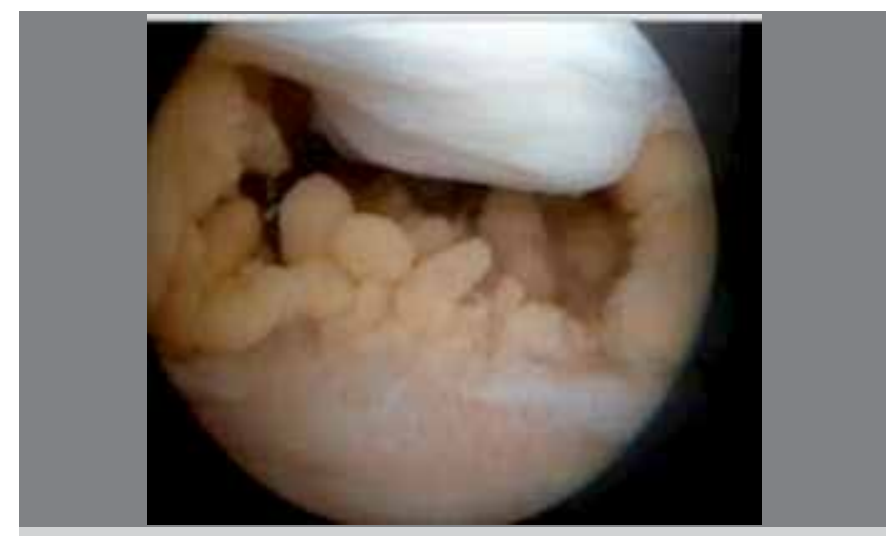

Figure 4. Arthroscopic image of the left knee: nodular image above and vilosities below.

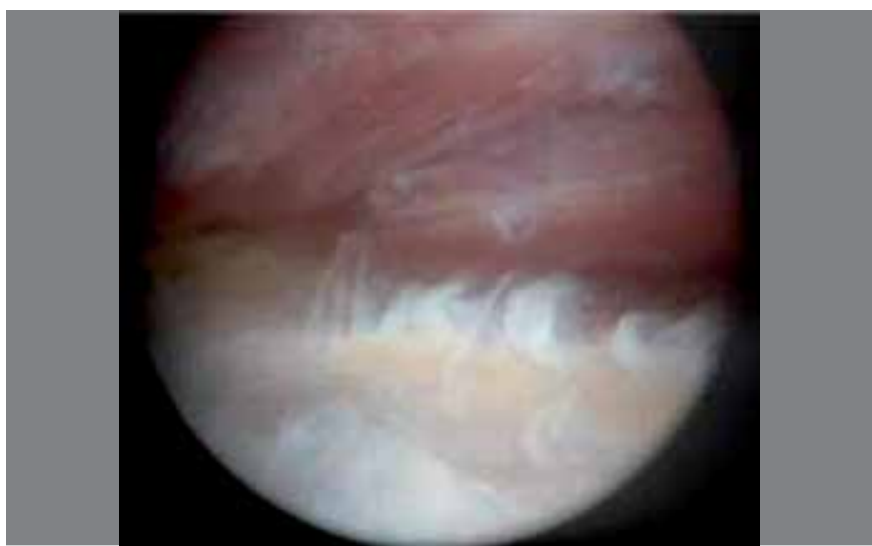

Figure 5. Arthroscopic image of the right knee. Capsule articular surface after synovectomy.

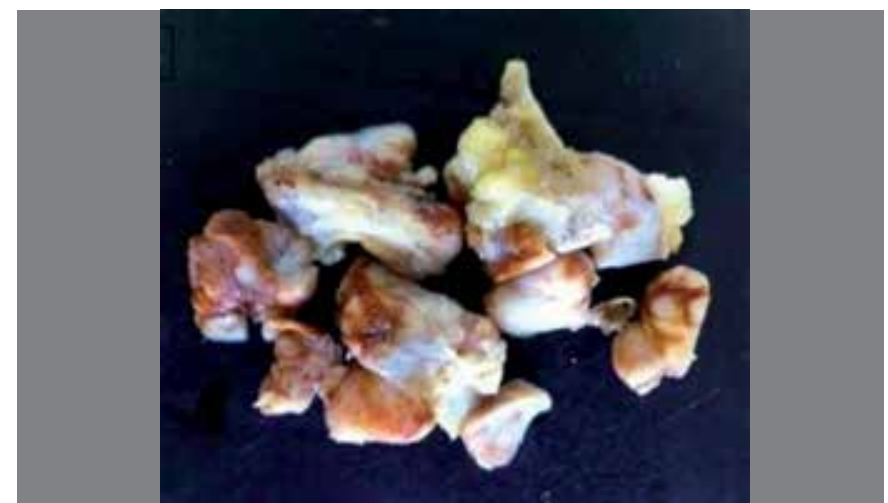

Figure 6. Macroscopic aspect of nodules after arthroscopic resection.

\section{DISCUSSION}

Pigmented villonodular synovitis (PVNS) is a rare disease characterized by proliferation of synovial tissue in the joint, tendon sheath, and bursa. The largest study on epidemiological features of PVNS was presented by Myers and Masi in 166 patients with an overall prevalence of 1.8 per million people. ${ }^{6}$ The knee was the most affected joint accounting for up to $80 \%$ of the cases. ${ }^{4,6}$

Histology of PVNS revealed a hypertrophic synovial process characterized by villous, nodular, and villonodular proliferation and hemosiderin pigmentation. The following forms are described: diffuse (when the entire synovium of joint is affected) or localized

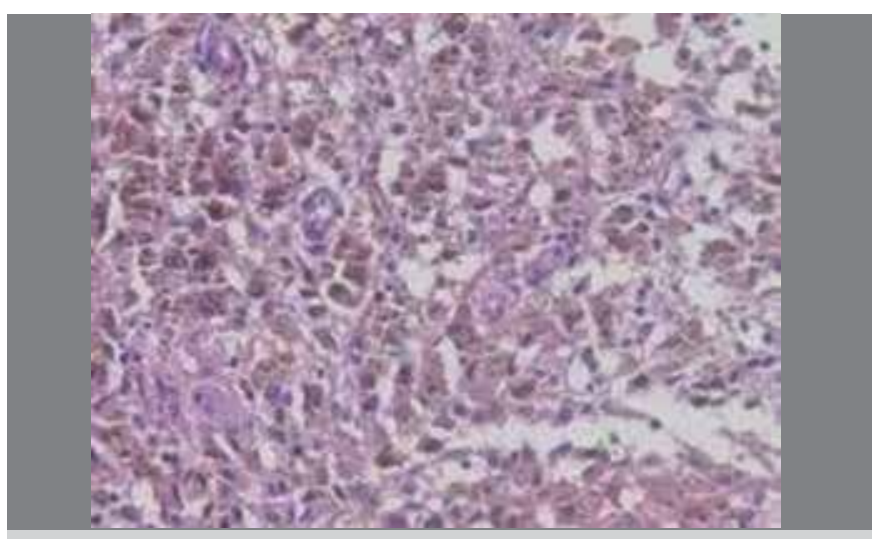

Figure 7. Microscopic H\&E 4X. Extensive areas with hemosiderin deposits (brown color).

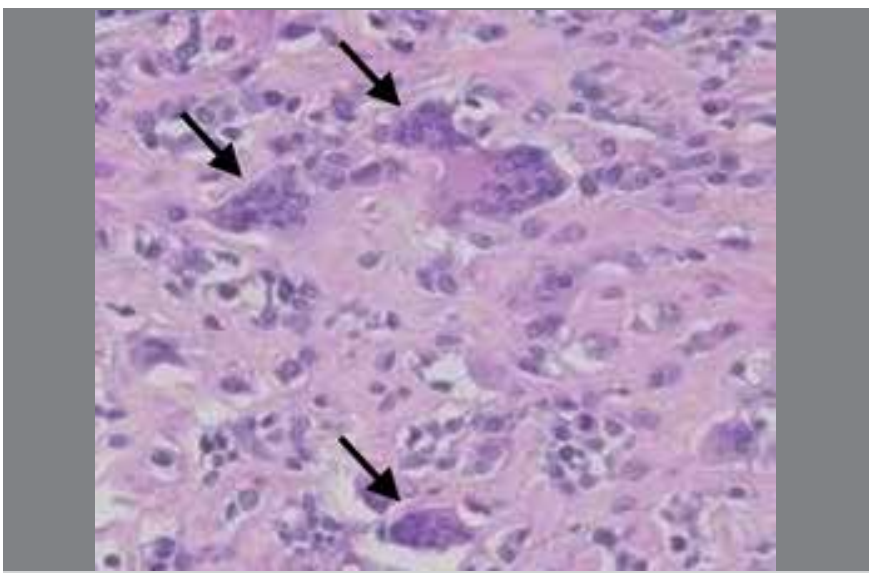

Figure 8. Microscopic H\&E 10X. Black arrows: Multinucleated giant cells.

(when a single compartment is affected). The diffuse intra-articular form of PVNS most frequently affects the large joints, with knee involvement in 66-80\% of the cases. Localized intra- articular involvement represents $6 \%$ of all cases. ${ }^{7}$

Some authors agree on the definition given by the World Health Organization (WHO). In this definition no difference is made between PVNS and tenosynovial giant cell tumor (TSGCT). ${ }^{8}$ Other authors defend that conventional pigmented villonodular tenosynovitis (PVNS) is a diffuse-type of TSGCT. ${ }^{9}$ One of the major problems PVNS is delayed diagnosis due to the insidious course of the disease. The time between onset of complaints and diagnosis may exceed months to years. This allows the focal disease to become gradually more aggressive and result in bone, muscle and tendon invasion. ${ }^{1}$

In most patients with the diffuse form, the diagnosis is easy, because of suggestive clinical findings (recurrent haemarthrosis with pain, stiffness, mirrored bone cysts, cortical erosion, and osteoarthritis). For some diffuse forms, but especially for the localized forms, non-specific symptoms makes this disease a challenging diagnosis. ${ }^{10}$ Discomfort is always present but the clinical presentation is variable according to Bouguennec et al.:10 locking (30-100\% of cases), effusion (53-90\%), diffuse pain (66-100\%), reduced range of motion (45\%), palpable mass (11-80\%) or pain over the joint line suggest a meniscal injury (10-34\%).

The clinical presentation can also suggest the presence of an intra-articular floating foreign body and symptoms related to cartilage injury are also possible. Bouguennec et al. ${ }^{10}$ stated that a preoperative diagnosis of meniscal injury was made in $30 \%$ of localized PVNS 
cases and the PVNS diagnosis was made in only $25 \%$ of localized forms. MRI helps with the diagnosis of diffuse forms as it detects areas of inflammation with hemosiderin deposits, and is also the best diagnostic imaging modality for evaluating soft tissue tumors. The localized forms are more challenging. AMRI shows a heterogeneous soft-tissue mass with T1 and T2 hyposignal. The signal is intermediate if only small hemosiderin deposits are present. These hemosiderin deposits are more visible with gradient echo sequences. The image on MRI could be confounded with haemangioma, fibroxanthoma, synovial chondromatosis and amyloid or haemophilic arthropathy. ${ }^{10}$ Another important differential diagnosis in this case report is lipoma arborescens. The MRI is the best method to differentiate this pathology. ${ }^{11}$

Differential diagnosis with lipoma arborescens (LA) in supra-patellar form is necessary due to the common localization and benign behavior that does require a surgical treatment. In this case, the presence of tenosynovial giant cells associated with hemosiderin pigmentation confirmed the diagnosis of PVNS.

$L A$ is a rare benign intra-articular lesion of unknown etiology which more frequently involves the suprapatellar pouch of the knee. ${ }^{12} \mathrm{LA}$ is characterized by replacement of the subsynovial tissue by mature fat cells giving rise to a villous proliferation. The characteristic feature is the macroscopic hypertrophic lipomatous synovial tissue..$^{13}$ The main findings of LA in MRI (the most specific method of diagnosis) are: a synovial mass with an arborescent, architecture and a signal intensity similar to that of fat on all pulse sequences, with suppression of the signal on STIR sequencing or pre-saturation of the fat; associated joint effusion potential chemical-shift artifacts at the fat-fluid interface within the joint and absence of magnetic susceptibility effects associated with hemosiderin. ${ }^{13}$ In our patient, the presence of tenosynovial giant cells associated with hemosiderin pigment confirmed PVNS diagnosis. MRI revealed presence of hemosiderin in T1 and T2 signal.
Over the past 100 years little progress has been made in treatment strategies. The aim of PVNS treatment, which consists a removal of all abnormal synovial tissue, is to relieve pain, lower the risk of joint destruction, and avoid local recurrence. In cases of residual or recurrent disease, other treatments modalities have been tried. Several options have been proposed for the knee joint - from observation to total knee arthroplasty, including external beam radiation, radioactive synovectomy, or surgical synovectomy. Depending on the synovial extension of PVNS, surgical synovectomy can be performed by open or arthroscopic techniques. Finally, some clinicians have suggested a combined treatment.

Unfortunately, because of the extremely low incidence of PVNS and the long disease free interval, large randomized controlled trials have not been performed and no large studies have clearly shown any superiority of one option over another. ${ }^{8,14,15}$

Acording to Verspoon et al., ${ }^{14}$ a study conducted in 2014 showed recurrence rates of $22 \%$ in 27 localized PVNS patients over an average 7.2 years. Recurrence rates of PVNS reduce with time. Long follow-up periods show that diffuse PVNS is a recurring disease becoming more difficult to treat as time passes by. These findings confirm the importance of differentiating PVNS subtypes and also suggest that patients should receive treatment(s) at tertiary centers because of its rarity and destructiveness. ${ }^{14}$

Complications described in literature are infections and stiffness. Than, iatrogenic loss of joint function is a possible complication of PVNS treatment that requires manipulation. ${ }^{14}$

\section{CONCLUSIONS}

The bilateral and localized forms are rare presentations of PVNS. This is only the third case reported in literature. Differential diagnosis with lipoma arborescens in the supra-patellar form is needed due to the common site localization and benign behavior that does not requires surgical treatment.

AUTHORS' CONTRIBUTIONS: Each author made significant individual contributions to this manuscript. TLF (0000-0002-6665-3608)* : was responsible for the integrity of the study from inception to completion; TLF and AJH (0000-0001-8645-3956)*: were involved in the conception and design of the study; TLF, LDV (0000-0002-9488-1763)*, SUS (0000-0001-8058-3610)*, AMA (0000-0003-2507-3786)*, and AJH collected and assembled the data; TLF, RJMN (0000-0002-4708-792X)*, LDV (0000-0002-9488-1763)* SUS, and AJH analyzed and interpreted the data. TLF, RJMN, LDV, AMA, AP (00000002-8449-7493)*, SUS, and AJH drafted the manuscript; TLF, RJMN, SUS, AMA, AP, and AJH conducted the critical revision. All authors contributed to the intellectual concept of the study and approved the final version of the manuscript. ${ }^{*}$ ORCID (Open Researcher and Contributor ID).

\section{REFERENCES}

1. Akinci $O$, Akalin $Y$, Incesu $M$, Eren $A$. Long-term results of surgical treatment of pigmented villonodular synovitis of the knee. Acta Orthop Traumatol Turc. 2011;45(3):149-55.

2. Chassaignac M. Cancer de la gaine des tendones. Gaz Hop Civ Milit. 1852; $47: 185-6$

3. Jaffe HL, Lichtensteins L, Sutro CJ. Pigmented villonodular synovitis, bursitis and tenosynovitis. A discussion of the synovial and bursal equivalents of the tenosynovial lesion commonly denoted as xanthogranuloma, giant cell tumor or myeloplaxoma of the tendon sheath, wth some consideration. Arch Patrol. 1941;31:731-65.

4. Klammer G, Betz M, Delaloye B, Farshad M, Peter KP. Bilateral diffuse pigmented villonodular synovitis of the knee. J Knee Surg. 2013;26(Suppl 1):S67-71.

5. Granowitz SP, D'Antonio J, Mankin HL. The pathogenesis and long term and results of pigmented villonodular synovitis. Clin Orthop Relat Res. 1976;(114):335-51.

6. Myers BW, Masi AT. Pigmented villonodular synovitis and tenosynovitis: a clinica epidemiologic study of 166 cases and literature review. Medicine (Baltimore). 1980;59(3):223-38

7. Ottaviani S, Ayral X, Dougados M, Gossec L. Pigmented villonodular synovitis: retrospective single-center study of 122 cases and review of the literature. Semin Arthritis Rheum. 2011;40(6):539-46.

8. Aurégan JC, Klouche S, Bohu Y, Lefèvre N, Herman S, Hardy P. Treatment of
Pigmented Villonodular Synovitis of the Knee. Arthroscopy. 2014;30(10):1327-41. 9. Ding Y, Griffin JE, Raghavan M, Xu H, Henderson-jackson E, Bui MM. Tenosynovial Giant Cell Tumors Lacking Giant Cells: Report of Diagnostic Pitfalls. Ann Clin Lab Sci. 2014;44(2):222-7.

10. Bouguennec N, Meyer A, Graveleau N. Localized form of pigmented villonodular synovitis of the knee: the meniscal mime. Orthop Traumatol Surg Res. 2014;100(2):3251-4.

11. Kim RS, Kim YT, Choi JM, Shin SH, Kim YJ, Kim L. Lipoma arborescens associated with osseous/chondroid differentiation in subdeltoid bursa. Int $\mathrm{J}$ Shoulder Surg. 2013;7(3):116-9.

12. Santiago M, Passos AS, Medeiros AF, Sá D, Correia Silva TM, Fernandes JL. Polyarticular lipoma arborescens with inflammatory synovitis. J Clin Rheumatol. 2009; 15(6):306-8.

13. Bejia I, Younes M, Moussa A, Said M, Touzi M, Bergaoui N. Lipoma arborescens affecting multiple joints. Skeletal Radiol. 2005;34(9):536-8.

14. Verspoor FG, Zee AA, Hannink G, van der Geest IC, Veth RP, Schreuder HW. Long-term follow-up results of primary and recurrent pigmented villonodular synovitis. Rheumatology (Oxford). 2014;53(11):2063-70.

15. Temple HT. Pigmented villonodular synovitis therapy with MSCF-1 inhibitors. Curr Opin Oncol. 2012;24(4):404-8. 